\title{
Association between Periodontal Status Sociodemographic Profile and Different Level of Oral Hygiene Status among Smokers
}

\author{
SYEDA GULRUKH SABA SHAH ${ }^{1}$, HAMMAL KHAN NASEER BALOCH ${ }^{2}$, SHAMS-UL-HAQ ${ }^{3}$, AFAQ $^{\prime}$ \\ SYEDALALARUKH SABA SHAH ${ }^{5}$, FARHANA JABEEN SHAH ${ }^{6}$ \\ ${ }^{1}$ Assistant Professor, Department of Anatomy, Sardar Begum Dental College Gandhara University, Peshawar \\ ${ }^{2}$ Associate Professor, Department of Community \& Preventive Dentistry, Dental Section, Bolan Medical College Quetta \\ ${ }^{3}$ Lecturer, Department of Community Medicine, Kabir Medical College Gandhara University Peshawar \\ ${ }^{4}$ Assistant Professor, Department of Periodontology, Sardar Begum Dental College Gandhara University, Peshawar \\ ${ }^{5}$ Assistant Professor, Department of Community Dentistry, Lahore Medical and Dental College, Lahore \\ ${ }^{6}$ Associate Professor, Department of Community Medicine, Kabir Medical College Gandhara University Peshawar \\ Correspondence to: Dr. Syeda Gulrukh Saba Shah, Email:gulrukhsaba321@gmail.com, Cell 0336-9678030
}

\begin{abstract}
Aim: Association between smoking and periodontal disease with sociodemographic profile and different levels of oral hygiene status.

Study Design: Case control study.

Place and Duration of Study: Khyber College of Dentistry and Sardar Begum Dental College and Hospital Peshawar KPK from $1^{\text {st }}$ July 2020 to $31^{\text {st }}$ December 2020.

Methodology: The were 300 patient from 20-50 years of age were enrolled in the study. The sample was stratified into two groups, cases and controls 150 patients in each group. Patients were clinically evaluated by measuring the PDI scores and oral hygiene index.

Results: There were (43.3\%) smokers and (56.6\%) were non-smokers. There were $57.3 \%$ smokers and $42.6 \%$ were non-smokers with periodontal disease the result was significant $(p=0.0001)$, while $29.3 \%$ smokers and $70.6 \%$ were non-smokers and did not have periodontal disease. The oral hygiene status was poor among smokers it was $23.1 \%$ while $2.9 \%$ among non-smokers, with significant result $p$-value was $=0.0001$. There was an association between periodontal disease with different levels of smoking the result was significant $(p=0.0001)$.

Conclusions: There was an association between smoking, sociodemographic profile with periodontal disease and oral hygiene status.

Keywords: Periodontal disease, Smokers, Non-smokers, Periodontal disease index, Oral hygiene index
\end{abstract}

\section{INTRODUCTION}

Periodontitis is an inflammatory disease of teeth and their supporting tissue. It is caused by a group of microorganisms. Which leads to severe gum recession with periodontal ligament distruction and alveolar bone loss which further initiated pocket formation around the teeth. ${ }^{1}$ The factors like pathogenic bacteria, tobacco chewing, plaque formation and microbial deposits around the teeth, among them smoking is also a risk factor for many disesese and affect health of the periodontium. Many investigators has also identified the role of tobacco smoking in the development of periodontal diseases. ${ }^{2}$ The world workshop in 1996, on periodontics reviewed many studies and stated that smoking is the known risk factor for periodontal disease with an odds ratio's $2.82 .^{3}$

Periodontal disease among smokers showed an increased prevalence of calculus and plaque as compared to non-smokers. Smokers are associated with increase attachment loss, furcation involvement on a radiograph, increase the pocket depth and alveolar bone loss.Smokingaffects host bacterial interaction and it also has an immunosuppressive effect on the host. ${ }^{4}$ Smoking cause a dose-dependent suppressive effect on gingival bleeding on probing. There is decrease gingival bleeding in smokers compared to non-smokers but the mechanism of gingival bleeding suppression is still not known. ${ }^{5}$ Smoking cigarettes have various unpleasant effects on dental and oral health. The impact of smoking is oral carcinomas, tooth loss, delayed healing of extraction sockets, bad breath, loss of taste and smell, discoloured tongue and teeth and periodontal problems. Smokeless tobacco causes tumours of the lip tongue and mouth and pancreas with periodontitis and destruction of gums. In five years of investigation, it was concluded that 800 tobacco consumers were in danger of attachment loss. In many epidemiological studies the association between periodontal disese and smoking has been reported there is decrease gingival bleeding in smokers as compared to non-smokers. After all, in smokers vasoconstriction occurs which further reduces gingival inflammation. ${ }^{6}$

Poor oral hygiene and lack of tooth brushing can encourage bacterial deposition and cause inflammation of periodontal tissue and the production of plaque on gums and teeth is also associated with periodontal disease. ${ }^{7}$ Axelsson et $\mathrm{al}^{8}$ conducted a prospective study for 15 years and found no destruction of periodontal structures in individuals who maintain and took routine professional dental care and practice proper tooth brushing.

Age is also a factor for an increase in periodontal disease, a high prevalence of periodontal disease was seen among aged individuals. ${ }^{9}$ Age is associated with the periodontal disease the attachment loss was obvious among individuals age $60-90$ years as compared to the individual age $40-50$ years. ${ }^{10}$

$\mathrm{WHO}$ recommends risk factors such as stress, socioeconomics and smoking are associated with periodontal disease. WHO include preventive strategies which can limit the burden of the disease at population level. ${ }^{11}$ 
Based on the observation that with less gingival inflammation and increase attachment loss this research is conducted to evaluate the association between periodontal status sociodemographic profile and different levels of oral hygiene status among smokers and non-smokers. In Pakistan, periodontal disease with poor oral hygiene is the major public health problem. These problems can be resolved by smoking cessation and by oral hygiene practice. There is a need for preventive strategies to stop periodontal disease among individuals.

\section{MATERIALS AND METHODS}

It was a case control study and comprised 300 patients visiting to OPD of dental hospitals Peshawar. They were divided in two groups; cases \& controls and each group comprised 150 ptietnts. The standardized questionnaire consists of a periodontal index and oral hygiene index was used and an interview was taken face to face among patients visiting the dental hospitals of KPK. To collect samples verbal informed consent was used for patients. The sample was collected from the periodontology department of dental hospitals. The patient was properly examined intraorally to assess the oral health and periodontal status of the smokers and non-smokers. Periodontal examination was performed for every individual seated in a dental chair in good light conditions and properly sterilized instruments were used. Examination of teeth was done by by periodontal probe. All the teeth were examined around the whole circumference. The highest score was recorded.For intra-oral examination of smokers and non-smokers periodontal probe, twizer, mouth mirror and explorer 23 was used. The outcome variables were oral health and periodontal status while age, location, smoking and education were independent variables. To assess the periodontal status periodontal disease index was used and oral hygiene index-simplified was used to assess oral health status among smokers and nonsmokers. The smokers were divided into three level based on daily consumption of cigarettes. They were divided as light smokers consuming $<10$ cigarettes per day, moderate smokers consuming $\geq 10$ to $<20$ cigarettes per day and heavy smokers consuming $\geq 20$ cigarettes per day. Tobacco chewers, mechanical irritant, chemical irritants, patients with immune disorders and congenital anomalies, blood disorders,patient having habits like attrition, nail biting and bruxism were excluded. The data was entered and analyzed through SPSS-20.

\section{RESULTS}

The association between age, education and periodontal disease with $p$-value 0.03 , while location is not significant $p$ value was 0.43 (Table 1). There was an association between smoking and periodontal disease while smoker from 31 to 40 were $62.3 \%$,from $20-30$ years $9.2 \%$ and from 41-50 they were $28.5 \%$ and the results was significant ,which shows association between age and smoking (Table 2). The use of cigarette was increased at the age of 31-40 years while smoking habit was very less in young adults as well as from 41 to 50 years (Table 3 ). There was an association between smoking and different level of oral hygiene status the result was significant $p$-value was 0.0001 (Table 4). Different level of smokers with periodontal disease the result was significant $p$-value was 0.001 (Table 5).

Table 1: Sociodemographic profile of patients with periodontal status $(\mathrm{n}=300)$

\begin{tabular}{|c|c|c|c|c|}
\hline Sociodemographic & $\mathrm{PD}^{+}$ & $\mathrm{PD}^{-}$ & $\chi^{2}$ & $\begin{array}{l}P \\
\text { value }\end{array}$ \\
\hline \multicolumn{5}{|l|}{ Age (years) } \\
\hline $20-30$ & $37(24.6 \%)$ & $41(27.3 \%)$ & \multirow{3}{*}{11.71} & \multirow{3}{*}{0.03} \\
\hline $31-40$ & $75(50 \%)$ & $80(53.3 \%)$ & & \\
\hline $41-50$ & $38(25.3 \%)$ & $29(19.3 \%)$ & & \\
\hline \multicolumn{5}{|l|}{ Education } \\
\hline Literate & $70(46.6 \%)$ & $31(20.6 \%)$ & \multirow{2}{*}{10.7} & \multirow{2}{*}{0.001} \\
\hline Illiterate & $80(53.3 \%)$ & $119(79.3 \%)$ & & \\
\hline \multicolumn{5}{|l|}{ Location } \\
\hline Rural & $60(40 \%)$ & $66(44 \%)$ & \multirow{2}{*}{1.8} & \multirow{2}{*}{0.43} \\
\hline Urban & $90(60 \%)$ & $84(56 \%)$ & & \\
\hline
\end{tabular}

Table 2: Association between smokers with periodontal status $(\mathrm{n}=300)$

\begin{tabular}{|l|l|l|l|l|}
\hline $\begin{array}{l}\text { Smoking } \\
\text { status }\end{array}$ & $\mathrm{PD}^{+}$ & $\mathrm{PD}$ & $\chi^{2}$ & $\mathrm{P}$ value \\
\cline { 1 - 3 } Smokers & $86(57.3 \%)$ & $44(29.3 \%)$ & \multirow{2}{*}{8.6} & 0.0001 \\
\hline Non-smokers & $64(42.6 \%)$ & $106(70.6 \%)$ & & \\
\hline
\end{tabular}

Table 3: Association between smoking and age $(\mathrm{n}=300)$

\begin{tabular}{|l|l|l|l|l|}
\hline $\begin{array}{l}\text { Age } \\
\text { (years) }\end{array}$ & Smokers & Non-smokers & $\chi^{2}$ & P value \\
\hline $20-30$ & $12(9.2 \%)$ & $62(36.5 \%)$ & \multirow{2}{*}{14.7} & \multirow{2}{*}{0.001} \\
\hline $31-40$ & $81(62.3 \%)$ & $84(49.4 \%)$ & & \\
\hline $41-50$ & $37(28.5 \%)$ & $24(14.1 \%)$ & & \\
\hline
\end{tabular}

Table 4: Different levels of oral hygiene status in smokers and nonsmokers $(n=300)$

\begin{tabular}{|l|l|l|l|l|}
\hline $\begin{array}{l}\text { OHI-S } \\
\text { score }\end{array}$ & Smokers & Non-smokers & $\chi^{2}$ & P value \\
\hline Good & $31(23.8 \%)$ & $148(87.1 \%)$ & \multirow{2}{*}{75.16} & 0.0001 \\
\hline Fair & $69(53.1 \%)$ & $17(10 \%)$ & & \\
\hline Poor & $30(23.1 \%)$ & $5(2.9 \%)$ & & \\
\hline
\end{tabular}

Table 5: Different level of smokers with periodontal disease $(\mathrm{n}=300)$

\begin{tabular}{|l|l|l|l|l|l|}
\hline Level of Smokers & PD $^{+}$ & PD $^{-}$ & Total & $\chi^{2}$ & P value \\
\hline Non-smokers & 64 & 106 & 170 & & \\
\cline { 1 - 4 } Light smokers & 42 & 23 & 65 & \multirow{2}{*}{42.6} & \multirow{2}{*}{0.0001} \\
\cline { 1 - 4 } Moderate smokers & 27 & 16 & 43 & & \\
\cline { 1 - 5 } Heavy smokers & 17 & 5 & 22 & & \\
\hline
\end{tabular}

\section{DISCUSSION}

The presence of periodontal disease can affect the quality of life of adult population. The present study revealed that patients from $31-40$ years got $50 \%$ of periodontal disease while patient from 20 to 30 years $24.6 \%$ and $25.3 \%$ in 40 50 years, which is in accordance to the study conducted in northwest Ethiopia population there were $57.30 \%$ individuals got the periodontal disease from 20-34 years while $24.15 \%$ in elderly individuals. ${ }^{12,13}$ In the present study, there were $42.6 \%$ of non-smokers are affected by the periodontal disease as compared to smokers which are according to the study conducted in the Ethiopian population that there were $42.3 \%$ of participants are affected by periodontal disease agreed with the study done in Addis Ababa $53.4 \%{ }^{14}$ and Arusi $52 \%{ }^{15}$ there is increase in periodontal disease in other studies done in Egypt 89.8\% ${ }^{16}$ and Sudan $63.9 \% .{ }^{17}$ 
Age itself is not the factor to cause and affect the severity of the disease rather it is the combined effect of other factors and the effect of untreated diseases. There was a significant association was found between socioeconomic like educational level, location and age with the periodontal disease. Smoking is also a factor for the causation of periodontal disease, in the previous study there was an association between smoking and periodontal disease, the study conducted in Ethiopia stated that $42.2 \%$ of the study population affected with the periodontal disease the study also confirm that sociodemographic profile including education, income, age education and location showed significant association with periodontal disease. Individuals who had no formal education were 3.25 times at the risk of periodontal disease. ${ }^{13}$

In the present study there was association between age, smoking and periodontal disease. The individual age from 30 to 40 years were affected by periodontal disease as compared to age from 20 to 30 and 40 to 50 years. The present study also showed a statistically significant association between education and location. The participants living in ruler areas are less susceptible to periodontal disease because individual living in rural area of $\mathrm{KPK}$ are tobacco chewers and the individual living in urban are smokers so the result is not significant which is against the agreement of other studies. ${ }^{10,11}$ In the present study majority of the smokers are found in urban areas of KPK. The result is not significant for ruler areas that area $p-$ value is 0.34 . In the present study $46.6 \%$ of individuals got periodontal disease as compared to illiterate $53.3 \%$ got the disease as they are not practising the daily tooth brushing and because of poverty and low socioeconomic status, the periodontal disease is more pronounced in illiterate as compared to literate. ${ }^{18,19}$

The participants above the age of 40 years had more periodontitis that is in agreement with other regional studies. It is not according to the present study the periodontal disease is more pronounced in 30 to 40 years as compared to 40 to 50 years. In kpk it was seen that at the age of 40 to 50 years most of the individuals quit smoking because of family pressure and other hazards of smoking, so the percentage of smokers are less in Peshawar from 40 to 50 years as compared to $30-40$ years. In the present study, oral hygiene is good among the nonsmokers as compared to smokers while oral hygiene was fair that is $53.3 \%$ patients had fair oral hygiene and $23.1 \%$ had poor oral hygiene status. There is poor oral hygiene $2.9 \%$ among non-smokers. Smoking is the risk factor for periodontal disease because it can change the human immune response and microflora of the oral cavity which leads to the destruction of the periodontal tissue that supports the teeth. In smokers, the immune system is depressed due to the decreasing number of lymphocytes which are responsible for the production of B-cell and antibodies in the body to play important role in the defence system. The combined effect of smoking and bacterial colonization cause an increase in the destruction of periodontium according to the study conducted by Linden and Mullally ${ }^{20}$,Schenkein et $\mathrm{al}^{21}$ and Haffajee \& Socransky. ${ }^{22}$ In these studies severity of the periodontal disease is higher in young adults but the duration is not recorded but socioeconomic status and stress were considered as a factor for the causation of the periodontal disease. The results of the present study were against the above mention studies because in Pakistan the religion, cultural values and family pressure on young adults prevent the habit of smoking in early life so there is a decrease in the severity of periodontal disease among young adults as compared to an individual from 30 to 40 years. In the present study periodontal disease is $62.3 \%$ in $30-40$ years of individuals and also periodontal disease among smokers was pronounced that is $57.3 \%$ while it is less prominent among non-smokers $42.6 \% .^{23}$

The mean OHI-S was higher in the smokers, which shows that smokers generally had poorer oral hygiene. Smoking causes stains and roughens the surface of the teeth which leads to plaque accumulation. This finding is similar to the present study there was poor oral hygiene in smokers as compared to non-smokers. ${ }^{24}$

The fifth national health and nutrition examination survey stated that light smokers had the less periodontal disease than non-smokers. In Japanese, study conducted with sample size 1,332 from 30 to 59 years stated that increase consumption of cigarettes increases the risk of periodontal disease in smokers. While heavy smokers taking $\geq 20$ cigarettes per day had 2.33 times increase periodontal disease whereas smokers of $\geq 20$ cigarettes per day had 5 times higher risk of periodontitis as mention in NHANES III survey. It is according to the present study that heavy smokers had increase periodontal disease as compared to light smokers and moderate smokers. ${ }^{25}$

The periodontal disease should be included in national health program. Many surveys like National oral health survey should be conducted for the understanding of the relationships between risk factors related to periodontal diseases. These risk factors can be identified and allow the individual to take oral therapy on time to get better results. It should be recommended that smokers should visit to a dentist for preventive procedures regularly and should encourage to quit smoking.

\section{CONCLUSION}

There was an association between smoking, sociodemographic profile with periodontal disease and oral hygiene status. The exception lies in urban and rural areas (location), the result is not significant.

\section{REFERENCES}

1. Novak JM. Carranza's clinical periodontology. $9^{\text {th }}$ ed. Philadelphia: WB Saunders, 2003.

2. Haber J, Wattles J, Crowley M, Mandell R, Joshipura K, Kent $R L$. Evidence for cigarette smoking as a major risk factor for periodontitis. J Periodontol 1993; 64(1): 16-23.

3. Papapanou PN. Periodontal diseases: epidemiology. Ann Periodontol 1996; 1(1): 1-36.

4. Kazor C, Taylor GW, Loesche WJ. The prevalence of BANAhydrolyzing periodontopathic bacteria in smokers. J Clin Periodontol 1999; 26(12): 814-21.

5. Dietrich T, Bernimoulin JP, Glynn RJ. The effect of cigarette smoking on gingival bleeding. J Periodontol 2004; 75(1): 1622.

6. Goyal J, Menon I, Singh RP, Gupta R, Sharma A, Bhagia P. Prevalence of periodontal status among nicotine-dependent individuals of 35-44 years attending community dental camps in Ghaziabad district, Uttar Pradesh. J Fam Med Primary Care 2019;8(7):2456. 
7. de Oliveira C, Watt R, Hamer M. Toothbrushing, inflammation, and risk of cardiovascular disease: results from Scottish Health Survey.BMJ2010;340:c2451.

8. Axelsson $\mathrm{P}$, Lindhe $\mathrm{J}$, Nyström $\mathrm{B}$. On the prevention of caries and periodontal disease. Results of a 15-year longitudinal study in adults. J ClinPeriodontol1991;18:182-9.

9. Grodstein F, Colditz GA, Stampfer MJ. Post-menopausal hormone use and tooth loss: a prospective study. J Am Dent Assoc 1996; 127:370-7.

10. Rheu GB, Ji S, Ryu JJ, Lee JB, Shin C, Lee JY, et al. Risk assessment for clinical attachment loss of periodontal tissue in Korean adults. J Adv Prosthodont 2011;3:25-32.

11. Petersen PE, Ogawa $H$. Strengthening the prevention of periodontal disease: The WHO approach. J Periodontol 2005;76:2187-93.

12. Chapple IL. Time to take periodontitis seriously. BMJ Publishing Group 2014.

13. Pihlstrom BL, Michalowicz BS, Johnson NW. Periodontal diseases. Lancet 2005; 366(9499):1809-20.

14. Simon C, Tesfaye F, Berhane Y. Assessment of the oral health status of school -children in Addis Ababa. Ethiop Med J 2003;41(3):245-56.

15. Olsson B. Periodontal disease and oral hygiene in Arussi province, Ethiopia. Community Dent Oral Epidemiol 1978; 6(3):139-45.

16. Abbass MM, Rady D, Radwan IA, et al. The occurrence of periodontal diseases and its correlation with different risk factors among a convenient sample of adult Egyptian population: a cross-sectional study. F Res 2020;8:1740.

17. Khalifa N, Allen PF, Abu-bakr NH, Abdel-Rahman ME, Abdelghafar KO. A survey of oral health in a Sudanese population. BMC Oral Health 2012;12(1):5.
18. Tefera A, Bekele B. Periodontal Disease Status and Associated Risk Factors in Patients Attending a Tertiary Hospital in Northwest Ethiopia. Clin Cosmet Investig Dent 2020; 12:485-92.

19. Akhtar SBH, Agha SM, Farrukh MI. Periodontal disease status and associated risk factors in patients attending a Dental Teaching Hospital in Rawalpindi, Pakistan. J Indian Soc Periodontol 2015; 19(6): 678-82.

20. Linden GJ, Mullally $\mathrm{BH}$. Cigarette smoking and periodontal destruction in young adults. J Periodontol 1994;65:718-23.

21. Schenkein HA, Gunsolley JC, Koertge TE, Schenkein JG, Tew JG. Smoking and its effects on earlyonset periodontitis. J Am Dent Assoc 1995;126:1107-13.

22. Haffajee AD, Socransky SS. Relationship of cigarette smoking to attachment level profiles. J Clin Periodontol 2001;28:283-95.

23. Gautam DK, Jindal V, Gupta SC, Tuli A, Kotwal B, Thakur R. Effect of cigarette smoking on the periodontal health status: a comparative, cross sectional study. J Indian Soc Periodontol 2011; 15(4): 383-7.

24. Arowojolu MO, Fawole OI, Dosumu EB, Opeodu OI. A comparative study of the oral hygiene status of smokers and non-smokers in Ibadan, Oyo state. Niger Med J2013; 54(4): 240-43..

25. Jang AY, Lee JK, Shin JY, Lee HY. Association between smoking and periodontal disease in Korean adults: The Fifth Korea National Health and Nutrition Examination Survey (2010 and 2012).Korean J Fam Med 2016; 37(2): 117-22. 